\title{
Estimating the Topography Before Volcanic Sector Collapses Using Tsunami Survey Data and Numerical Simulations
}

\author{
Yusuke Yamanaka $^{1,2}$ and Yuichiro TANioka ${ }^{1}$
}

\begin{abstract}
Large sector collapses and landslides have the potential to cause significant disasters. Estimating the topography and conditions, such as volume, before the collapse is thus important for analyzing the behavior of moving collapsed material and hazard risks. This study considers three historical volcanic sector collapses in Japan that caused tsunamis: the collapses of the Komagatake Volcano in 1640, Oshima-Oshima Island in 1741, and Unzen-Mayuyama Volcano in 1792. Numerical simulations of the tsunamis generated by each event were first carried out based on assumed collapse scenarios. The primary objective of this study is to present conditions related to the topography before the events based on inverse models of the topography from those results and tsunami survey data. The Oshima-Oshima Tsunami, which is the subject of many previous studies, was first simulated to validate the model accuracy and evaluate how run-up heights changed during the simulation as the topographic conditions changed. The run-up height was especially sensitive to the collapsed volume and frictional acceleration affecting the collapsed material; however, the observed run-up heights could be reproduced with high accuracy using proper conditions of frictional acceleration for the scenarios, even if they were not exact. A minimum requirement for the collapsed volume to generate the observed run-up height was introduced and quantitatively evaluated using the results of numerical tsunami simulations. The minimum volumes of the collapses of the Komagatake and Unzen-Mayuyama volcanoes were estimated to be approximately 1.2 and $0.3 \mathrm{~km}^{3}$, respectively.
\end{abstract}

Key words: Sectorcollapse, topography, numerical simulation, the 1640 Komagatake Tsunami, the 1741 Oshima-Oshima Tsunami, the 1792 Ariake-Kai Tsunami.

\section{Introduction}

Although large sector collapses and landslides are not frequent, they have the potential to threaten human life and cause large damages. For example,

1 Institute of Seismology and Volcanology, Hokkaido University, Kita 10 Nishi 8, Kita-ku, Sapporo 060-0810, Japan. Email: yamanaka@sci.hokudai.ac.jp

2 Research Fellow of the Japan Society for the Promotion of Science, Tokyo, Japan.
Mount St. Helens, which is located in Washington, USA, is known to be a mountain that partially collapsed in 1980 (Voight 1981) and subsequently generated a 2-3 $\mathrm{km}^{3}$ lock slide (Voight et al. 1981) that caused human fatalities and the damage of facilities. This event also produced a tsunami with a run-up height of $260 \mathrm{~m}$ in Spirit Lake located on the north side of the mountain (Voight et al. 1983). Understanding the behavior of collapsed material during an event is thus important for disaster mitigation. Numerical simulation is an effective measure to estimate how and where collapsed material propagates during the collapse. The simulation requires the initial conditions such as the collapse volume and initial position of the volume. Such initial conditions must first be estimated. For example, Lowder and Carmichael (1970) estimated the topography of the caldera of the Talasea Peninsula in Australia before the collapse (pre-event topography) based on the assumption that the elevation of the original mountain was $2500 \mathrm{~m}$; the collapsed volume was subsequently estimated to be $75 \mathrm{~km}^{3}$. Collapsed material of the Ritter Island Volcano in Papua New Guinea in 1888 rushed into the sea facing the island and caused a tsunami. Based on the results of a bathymetric survey near the island, Johnson (1987) estimated that the collapse volume of the island was approximately $4-5 \mathrm{~km}^{3}$. Ward and Day (2003) assumed the volume to be $4.6 \mathrm{~km}^{3}$ and showed that the observed features of the 1888 Ritter Island Tsunami were reproduced in a numerical simulation of the tsunami based on that assumption. Roverato et al. (2011) performed a stratigraphic study of debris avalanche deposits caused by the collapse of the Colima Volcano in Mexico and estimated the preevent topography based on several assumptions. 
Based on their results, they estimated an expected amount of deposits from the mountain to the area, where the stratigraphic survey was carried out. As described above, the pre-event topography has been estimated from the perspective of geological vestiges for the collapse or an imaginative scenario.

As mentioned above, sector collapses and landslides entering confined and open water bodies (lake, river, and ocean) commonly generate tsunamis (e.g., McFall and Fritz 2016). A well-known landslide-triggered tsunami was caused by a 7.8-magnitude earthquake in the Lituya Bay Fjord (U.S.) in 1958, This is the largest tsunami known to human kind, with a run-up height of $524 \mathrm{~m}$ (Miller 1960). Several studies have shown that the tsunami generated by this landslide could produce that height (e.g., Fritz et al. 2001, 2009; Weiss et al. 2009; Xenakis et al. 2017). There are many other historical tsunamis that were caused by sector collapses worldwide; the observed/expected tsunami characteristics (e.g., height) have been numerically simulated under assumed scenarios related to those collapses (Tinti et al. 2000; Zaniboni et al. 2013; Satake 2007). The relationships between the sector collapse and generated tsunamis have been widely investigated based on experimental and numerical studies (e.g., Fritz et al. 2003a, b, 2004; Sælevik et al. 2009; Mohammed and Fritz 2012; Heller and Spinneken 2013; McFall and Fritz 2016). Fritz et al. (2004), for example, investigated the relationship between an object rushing into the water and generating waves based on laboratory experiments. They suggested to classify the generated waves into four types based on factors such as slide Froude number and thickness: weakly nonlinear oscillatory wave, nonlinear transition wave, solitarylike wave, and dissipative transient bore. Mohammed and Fritz (2012) performed experimental studies using deformable objects as collapsed material and pointed out that the tsunami generation is influenced by certain parameters of the objects rushing into the water such as the velocity, thickness, length, and width. Sælevik et al. (2009) performed experimental and numerical studies and found that the volume of the objects governs the tsunami amplitude. There are many experimental and numerical studies of tsunamis based on specific collapse conditions (e.g., pre-event topography, object shape, volume, and material); however, there are no studies that estimate the pre-event topography by exclusively using the run-up heights from the tsunami survey. Considering the abovementioned reports, run-up or inundation heights are strongly related to the collapse conditions such as volume, material, and kinematic energy (McFall and Fritz 2016); it is expected that this information could be useful to estimate the pre-event topography and conditions using numerical tsunami simulation.

The present study considers three historical collapse events in Japan that generated tsunamis: the collapse of the Komagatake Volcano in 1640, Oshima-Oshima Island in 1741, and UnzenMayuyama Volcano in 1792 (Fig. 1). Numerical simulations of these events considering the uncertainty of the assumed scenarios were carried out and the pre-event topographies and collapse conditions, such as the volume, were estimated based on the results of the simulations and tsunami survey data.

\section{Model Setup for Numerical Simulations}

Many numerical models for simulating tsunamis due to sector collapse and landslides are available and

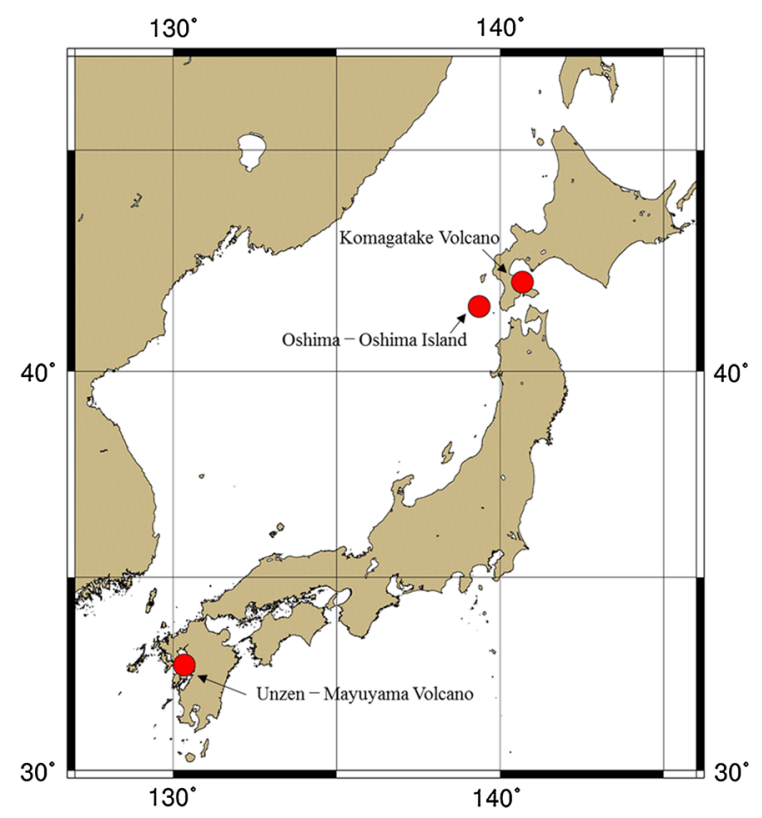

Figure 1

Location of each event 
have been applied to many events worldwide (Satake 2007; Løvholt et al. 2008; Xiao et al. 2015; Zaniboni et al. 2016; Kirby et al. 2016; de la Asunción et al. 2016). In general, numerical models of tsunamis associated with those events include a variety of subjective parameters to simulate the motion of the collapsed material represented by a frictional coefficient. The model of Xiao et al. (2015) is a two-layer model coupling the motions of water and collapsed material; however, it includes a few subjective parameters. This is a significant advantage compared with other models with respect to estimating their sensitivity to run-up heights derived from the uncertainty. This study then adopted the method of Xiao et al. (2015) to simulate the soil motion associated with a collapsing volcano; Fig. 2 briefly explains their methodology. As shown in Fig. 2, this approach employs a fixed bed topography, an initial height distribution of the collapsed material of the volcano (collapsed layer), and a collapse area. The collapsed layer should first be assumed based on the collapse area. It can move downward over the fixed bed towards the ocean under the effects of gravitational acceleration, depending on the horizontal slope gradient. Moreover, the ground elevation at each grid point evolves over time depending on the movement of the collapsed layer based on the acceleration (Fig. 2). Here, two frictional accelerations act on the collapsed layer in the opposite direction of the gravitational acceleration: basal and dynamic friction accelerations. They decrease the kinematic energy of the moving materials during the collapse. Including these parameters, the total acceleration acting on the collapsed layer is written as follows (Xiao et al. 2015):

$$
a=g \nabla \cdot z-C_{b} g v^{\prime}-C_{d} \frac{v|v|}{H}
$$

where $g$ is the acceleration due to gravity; $z$ is the ground elevation; $C_{\mathrm{b}}$ is the basal friction coefficient; $C_{\mathrm{d}}$ is the dynamic friction coefficient; $v^{\prime}$ is the unit velocity vector; $v$ is the velocity; and $H$ is the thickness of the collapsed materials. This method can estimate the change in the ground elevation over time by estimating the change in the velocity and thickness of the collapsed layer over time associated with the accelerations. For the detailed computational process, please refer to Xiao et al. (2015). They applied this method to the 2008 Gongjiafang Landslide and its tsunami and obtained good results, highlighting that their method has important advantages with respect to the computational efficiency.

Because tsunamis generated by sector collapse and landslides have been considered to have strong nonlinear and dispersion effects, those effects should be taken into account when simulating water motion

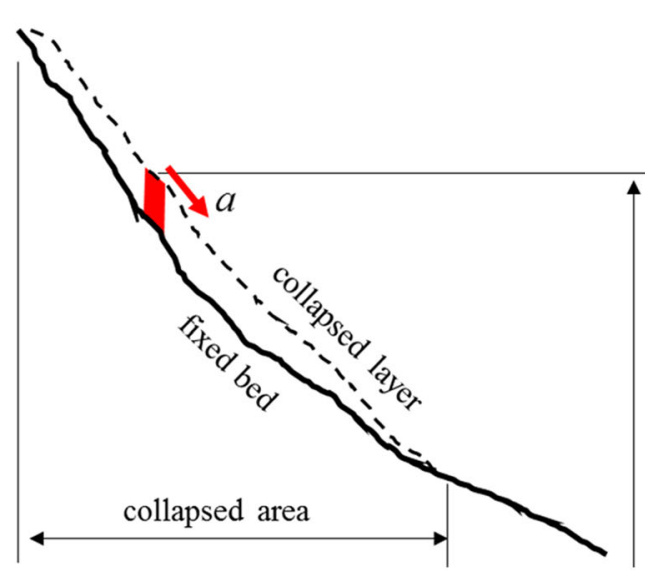

(a)

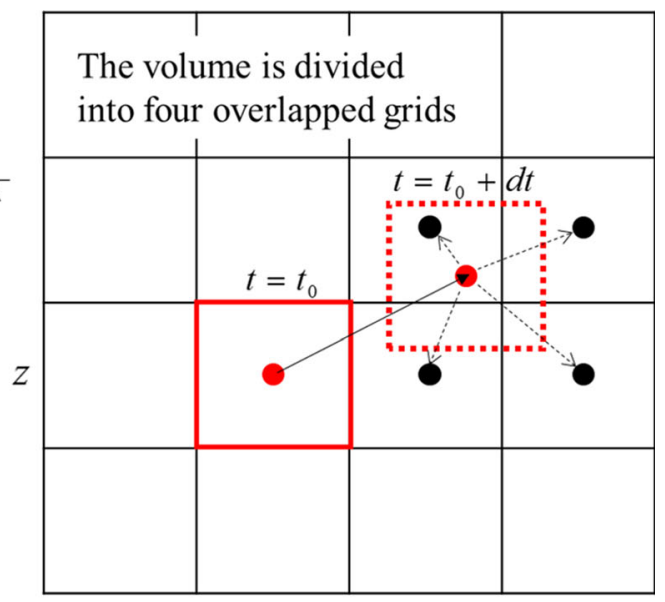

(b)

Figure 2

Concept of Xiao et al. (2015). a Cross-sectional view. b Top view 
(Watts et al. 2003; Zhou et al. 2011). In this study, the nonlinear dispersive wave theory expressed below (Boussinesq model), which is the same as that in Sato (1996), is used:

$$
\begin{gathered}
\frac{\partial(\eta-z)}{\partial t}+\frac{\partial P}{\partial x}+\frac{\partial Q}{\partial y}=0, \\
\frac{\partial P}{\partial t}+\frac{\partial}{\partial x}\left(\frac{P^{2}}{D}\right)+\frac{\partial}{\partial y}\left(\frac{P Q}{D}\right)+g D \frac{\partial \eta}{\partial x} \\
+\frac{g n^{2}}{D^{7 / 3}} P \sqrt{P^{2}+Q^{2}} \\
=\frac{h^{2}}{3} \frac{\partial}{\partial t}\left(\frac{\partial^{2} P}{\partial x^{2}}+\frac{\partial^{2} Q}{\partial x \partial y}\right), \\
\frac{\partial Q}{\partial t}+\frac{\partial}{\partial y}\left(\frac{Q^{2}}{D}\right)+\frac{\partial}{\partial x}\left(\frac{Q P}{D}\right)+g D \frac{\partial \eta}{\partial y} \\
+\frac{g n^{2}}{D^{7 / 3}} Q \sqrt{P^{2}+Q^{2}} \\
=\frac{h^{2}}{3} \frac{\partial}{\partial t}\left(\frac{\partial^{2} Q}{\partial y^{2}}+\frac{\partial^{2} P}{\partial x \partial y}\right) .
\end{gathered}
$$

where $\eta$ is the water surface elevation; $z$ is the ground elevation; $P$ and $Q$ are the flow rates in the $x$ and $y$ directions, respectively; $D(\eta+h)$ is the total depth; $h$ is the still water depth; and $n$ is Manning's roughness coefficient. A term to change the ground elevation was added to the equations of Sato (1996) and the diffusion terms were neglected. Because the Boussinesq model has produced good results for tsunami propagation and inundation of various events (e.g., Sato 1996; Baba et al. 2015), it was applied to simulate the water motion instead of using the method of Xiao et al. (2015). The governing equations were discretized based on a staggered leapfrog method and two-step mixed finite-differential scheme (Goto et al. 1997; Saito et al. 2014). The first nonlinear advection terms of Eqs. (3) and (4) were discretized using a third-order upwind scheme; the other nonlinear advection terms were discretized using a first-order upwind scheme. The moving landwater boundary conditions were modeled by Hirayama and Hiraishi (2004) using the overflow formula. Manning's roughness coefficient was assumed to be $0.025 \mathrm{~m}^{-1 / 3} \mathrm{~s}$ for the water area and $0.030 \mathrm{~m}^{-1 / 3} \mathrm{~s}$ for the land area. The tsunamis were simulated based on the changes in the ground elevation over time using the method of Xiao et al. (2015) and Eq. (2). Note that the collapsed layer is assumed to be able to move only when its thickness is greater than $0.1 \mathrm{~m}$. Moreover, the model in this study is implicitly based on the assumption that the generated tsunamis have little directivity, because the changes in ground elevation only lift the water surface up according to the governing equations. Additional acceleration due to the direct transfer of momentum from the collapsed material affects the water when it rushes into the sea or moves along the sea bottom; this generates wave directivity. Xiao et al. (2015) accounted for this effect, but it affects only in the shallow water area. The areas with deepwater depth are widely expanded near the OshimaOshima Island. Furthermore, this effect is expected to play a significant role when the front of slide material rushes into the sea. All the three events were largescale collapses; the scale of the slide material must also be large. Thus, the tsunami generation due to the uplift of the water surface would be dominant rather than that due to the direct transfer of momentum. The effect of wave directivity due to the direct transfer of momentum is expected to be small for the observed run-up heights; it is thus neglected in this study.

\section{Numerical Simulation of Tsunamis}

\subsection{Model Validation for the Oshima-Oshima Event}

The Oshima-Oshima Island in Hokkaido collapsed in 1741 because of volcanic activity. Its collapse caused a tsunami referred to as the OshimaOshima Tsunami. This tsunami killed more than a thousand people; the maximum run-up height was nearly $20 \mathrm{~m}$ (Hatori 1984). Many studies investigated the evidences of the collapse and run-up heights. Kato (1997) surveyed subaqueous collapse materials on the seafloor resulting from the sector collapse. Satake and Kato (2001) estimated the pre-event topography and that after the collapse (post-event topography) based on the results of Kato (1997). Kawamata et al. (2005) performed numerical simulations of tsunamis using the pre-event topography estimated by Satake and Kato (2001) and their own numerical model of coupling motions in soil and water layers (two-layer model). They succeeded in producing run-up heights that agree well with the 
observed heights. Satake (2007) also performed numerical simulations of tsunamis on the same preevent topography using his numerical model, which differs from the model used in Kawamata et al. (2005). His method for modeling the soil motion is called the Kinematic Land Slide Model. It is characterized by two parameters: slide velocity of the collapsed material and rise time of topography changes. He was also able to reproduce run-up heights that agreed with the observed heights. All of the collapsed material of the Oshima-Oshima event might be on the seafloor, because the collapsed layer/ area included not only land but also the sea. Therefore, it can be considered that the volume of subaqueous collapse material directly corresponds to the total collapse volume. Thus, the pre-event topography reconstructed by Satake and Kato (2001) using the results of Kato (1997) should be correct. Moreover, the results of Satake (2007) and Kawamata et al. (2005) who successfully reproduced the run-up heights using different numerical models based on the topography also support this conclusion. The Oshima-Oshima event was then simulated to validate the model accuracy of this study in terms of the runup heights.

The numerical model of this study considers two coefficients for residential accelerations affecting the collapsed material. However, the actual values or the appropriate combination of values remain unknown, because they depend on many factors such as the mechanism of collapse, weather, grain size, and grain shape. It is, therefore, difficult to uniquely determine the coefficients considering all factors. Hence, we first evaluated their sensitivities for the 1741 Oshima-Oshima Tsunami using the same topographic conditions.

Figure 3 displays the pre-event and post-event topographies of Oshima-Oshima Island estimated by Satake and Kato (2001). We first determined the collapsed area and fixed bed heights; the expected volume that the island used to have was used as the collapsed layer. A time evolution of the collapse was simulated based on these initial conditions. For tsunami computation, non-reflective boundary conditions based on the method of characteristics were set for the offshore boundaries. The computational domain was reconstructed from that of Satake and
Kato (2001) in spherical coordinates to a rectangular domain with a range of 58,650-273,000 $\mathrm{m}$ in the north-south direction and $-188,000$ to $-29,150 \mathrm{~m}$ in the east-west direction in the Japanese plane rectangular coordinate system No. 10. The Oshima-Oshima Island is located in the Sea of Japan with few oceanlevel changes due to tides; the initial water surface elevation was hence set to zero. The spatial grid size and time step are $150 \mathrm{~m}$ and $0.1 \mathrm{~s}$, respectively. The computations, including tsunami inundation, were performed for $90 \mathrm{~min}$ after the collapse started.

The computations were first performed for various values of the dynamic friction coefficient and a constant basal friction coefficient $\left(C_{\mathrm{b}}=\right.$ const $\left.=0.01\right)$; these computations were also performed for various values of the basal friction coefficient with a constant dynamic friction coefficient $\left(C_{\mathrm{d}}=\right.$ const $\left.=0.01\right)$. Xiao et al. (2015) determined the basal and dynamic friction coefficients for the 2008 Gongjiafang Landslide event that best match the model results and field survey data. However, the ranges of those values for other events are unknown. Sako et al. (2015) reported dynamic friction coefficients of 20 landslide events in Japan, China, Canada, and the U.S., which were identified by their simulations; the minimum value was approximately 0.01 . Considering the possibility that basal or dynamic friction coefficients of this study are of the same order, the minimum value of both frictional coefficients in the sea was set to 0.01 in this study. Moreover, the dynamic friction coefficient on land is a quarter of that of the sea, as reported in Xiao et al. (2015). The accuracy of the results for the observed run-up heights was quantitatively evaluated using indexes suggested by Aida (1978). He suggested two parameters to evaluate the fidelity of the estimations and observations; these parameters are the values of the geometric average $K$ and the geometric standard deviation $\kappa$, which depend on the number of observations, $m$. Good results are reflected by values of $K$ close to 1.0 and small values of $\kappa$. A values of $K$ smaller than 1.0 shows that the estimated run-up heights tend to be overestimated; in contrast, a value of $K$ greater than 1.0 shows that the run-up heights tend to be underestimated. The maximum water surface elevations at locations closest to the observation sites were determined to be the run-up heights 

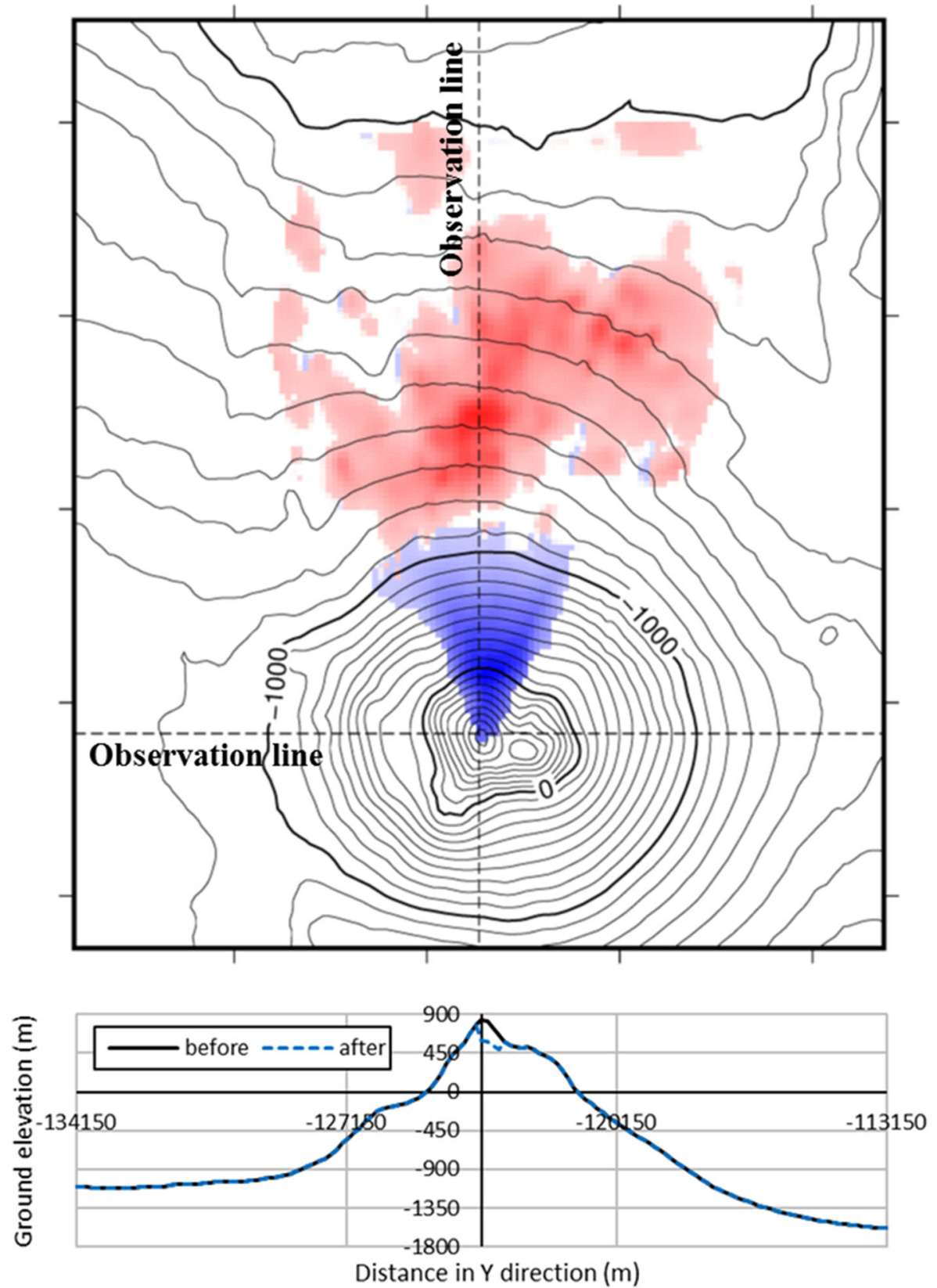

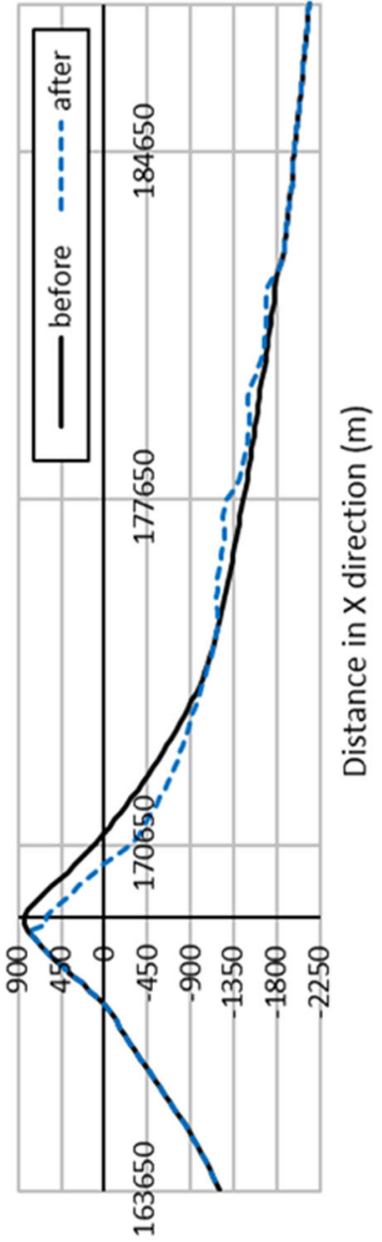

Ground elevation (m)

Figure 3

Topography of Oshima-Oshima Island estimated by Satake and Kato (2001) (the contour lines, separated by $100 \mathrm{~m}$, show the topography before the collapse; areas with red and blue colors show positive and negative height changes, respectively, of the ground elevation due to the collapse. The graphs show the ground elevation along the observation lines)

in the computations if the observation sites were not inundated. Moreover, the observational data were based on the height information of the Japan Tsunami Trace database (Iwabuchi et al. 2012). The observational data in this database are divided into six groups, $\mathrm{A}, \mathrm{B}, \mathrm{C}, \mathrm{D}, \mathrm{X}$, and $\mathrm{Z}$, depending on the reliability. This study used data with high reliability; these data belong to groups $\mathrm{A}$ and $\mathrm{B}$.

Figures 4 and 5 show the comparison of the runup heights and changes in the indexes as the assumed 


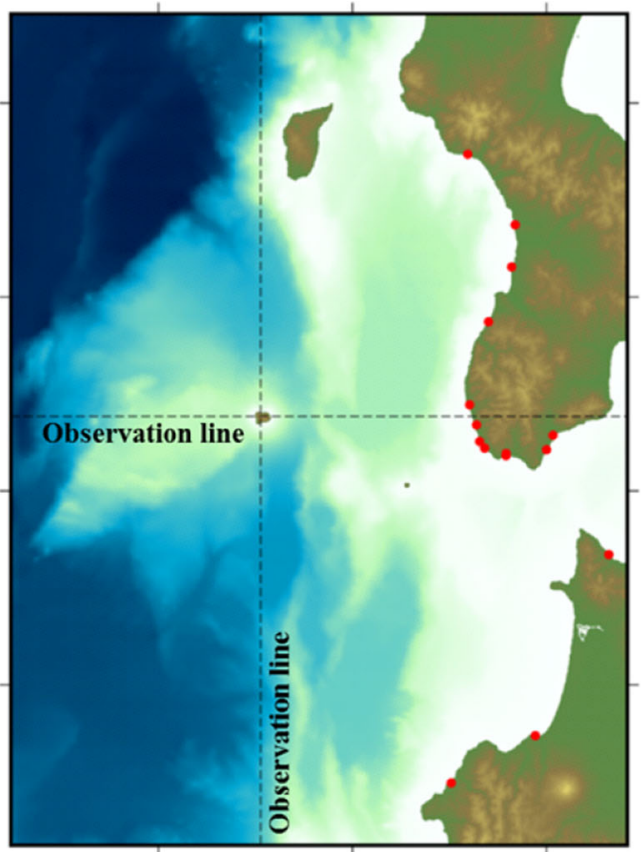

(a)
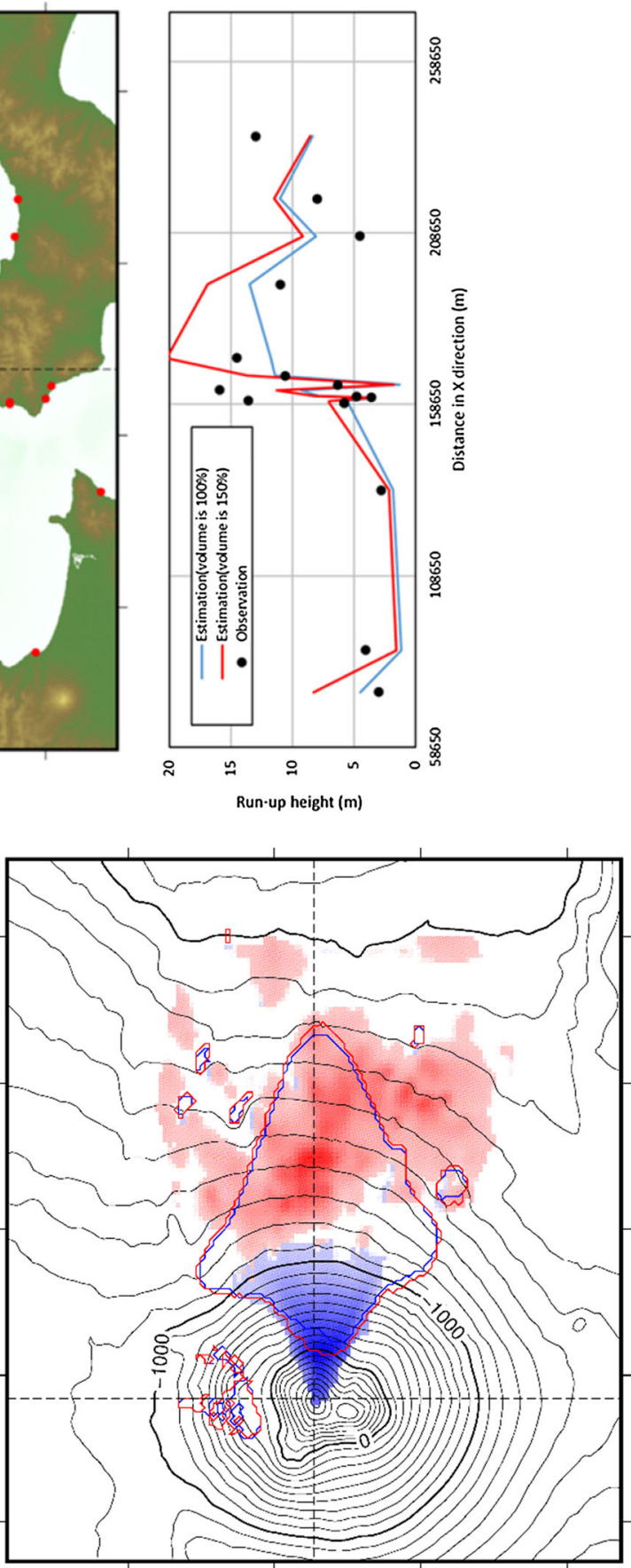

(c)

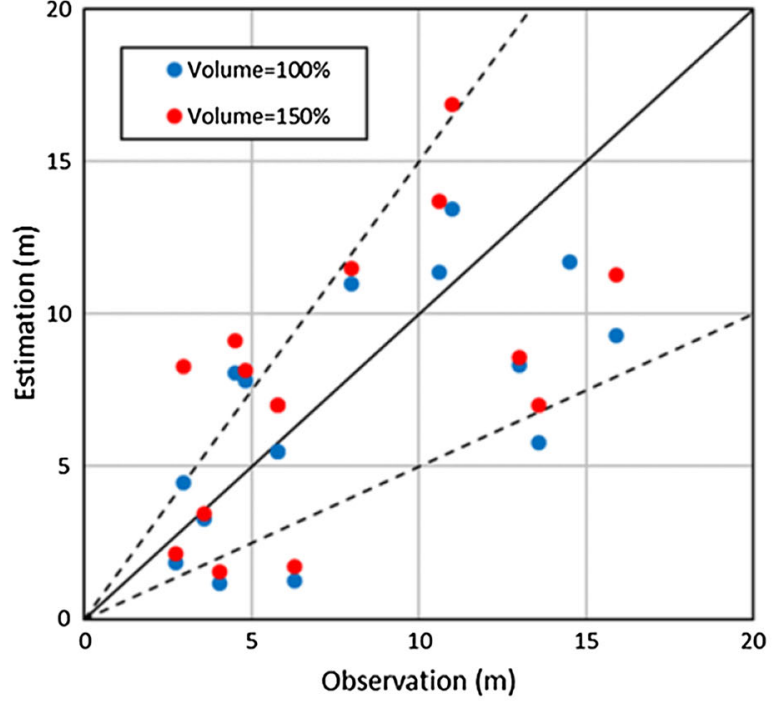

(b)

Results of the computations for the Oshima-Oshima Tsunami. a Computation domain and distribution of observed run-up heights (circles). b Comparisons of run-up heights $(K=1.23$ and $\kappa=1.91$ when the volume is $100 \% ; K=1.00$ and $\kappa=1.83$ when the volume is $150 \%$. The broken lines indicate a 50\% estimation error). c Distribution of the collapsed materials 90 min after the collapse (red and blue colors show positive and negative height changes, respectively, of the ground elevation due to the collapse. Red and blue lines show the estimated area in the cases that the collapsed volumes were 150 and $100 \%$ ) 


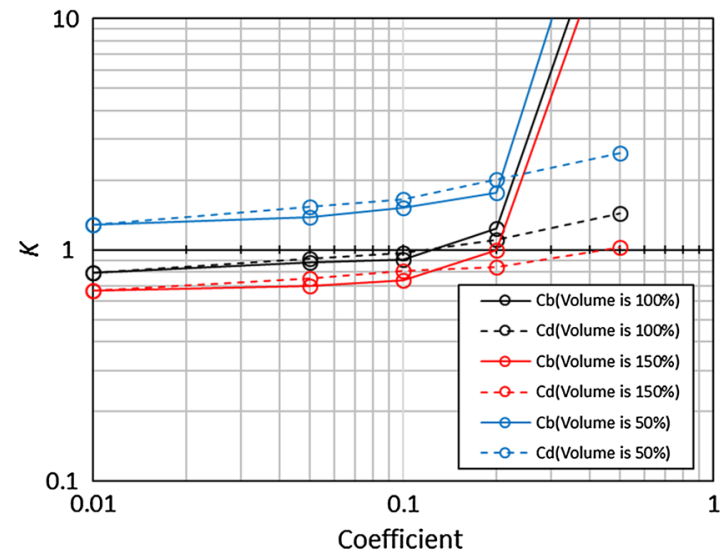

(a)

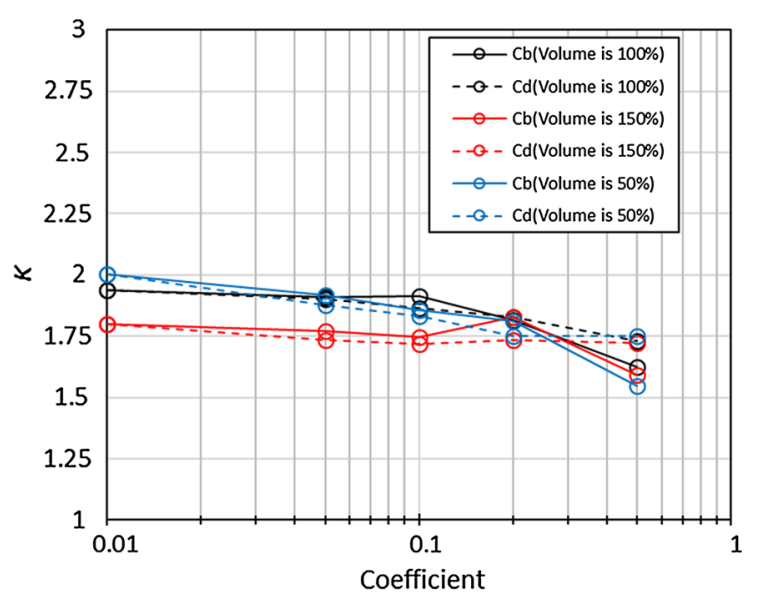

(b)

Figure 5

Sensitivity of the scenarios for the observation depending on the frictional coefficients

frictional coefficients change. Figure 4 indicates that relatively large run-up heights occurred on the northern side of the Oshima-Oshima Island compared with the southern side, because the northern side front of the Oshima-Oshima Island collapsed and its material moved towards the north. The estimated run-up heights showed a good agreement with the observed run-up heights, because the index $K$ is close to 1.0; the model of this study was then validated in terms of the run-up height. On the other hand, as shown in Fig. 5, both frictional effects seem to be sensitive to $K$ but not $\kappa$. Both lines of $C_{\mathrm{d}}$ and $C_{\mathrm{b}}$ were drawn over areas with over/underestimated runup heights. The $K$ value tends to show a monotonic increase as both frictional coefficients increase, because increasing values of frictional accelerations decrease the kinematic energy of the moving collapse material and the generated tsunami decreases in size. Moreover, the computations were performed under the assumption that the collapsed volume was oneand-a-half times and half that suggested by Satake and Kato (2001; Figs. 4 and 5). When the collapsed volume was assumed to be much larger than 1.0, that is, the volume was assumed to be $150 \%$, the index $K$ approached reasonable values using relatively larger frictional coefficients. Furthermore, as shown in Fig. 4, estimated distribution of collapse material does not match with observed distribution. This is considered to be because both frictional coefficients do not change with time and space. On the other hand, the estimated distributions with scenarios of 100 and $150 \%$ collapsed volume are very similar. These results indicate that any collapsed volume that is not smaller than a certain fixed volume is ostensibly likely to be good for the computation of run-up heights when the proper values of the coefficients are used for each scenario; in other words, it is difficult to quantitatively determine the collapsed volume from the run-up heights and distribution of the collapsed material.

In contrast, when the collapsed volume was insufficient compared with the actual volume, as shown in the case of a volume of $50 \%$, the index $K$ did not reach 1.0, regardless of the chosen coefficients. A minimum required collapsed volume for an observed tsunami can, therefore, be estimated using the following process. First, numerical tsunami simulations are performed with an assumed condition for the collapsed volume by changing the combinations of values of both coefficients. The $K$ values of each result are then evaluated and the simulations are performed again assuming an increase of the collapsed volume if $K$ is larger than the criterion. This approach is repeated until $K$ becomes smaller than the criterion; the requirement for the observed run-up heights is determined when this condition is satisfied. In this study, the criterion was set to 1.2 ; this value means that the estimated run-up heights tend to be underestimated by $20 \%$ on average compared with the observed heights. This rule was also applied to other events and the minimum required collapsed volumes were estimated. 


\subsection{Estimating the Minimum Requirements}

\subsubsection{The Komagatake Event}

The Komagatake Volcano in Hokkaido collapsed in 1640 due to volcanic activity, which caused a tsunami called the Komagatake Tsunami. The 1640 Komagatake Tsunami killed approximately 700 people. Evidence of the tsunami run-up height was obtained at an elevation of nearly $10 \mathrm{~m}$ by Nishimura and Miyaji (1995). Initially, the pre-event and post-event topographies are constructed using the DEM (Digital Elevation Model) data from the Geospatial Information Authority of Japan (GSI) and the Japan Hydrographic Association (JHA; Fig. 6). The present topography was first constructed based on those data. Second, the collapsed area of the volcano was specified based on a previous study (Yoshimoto et al. 2003) and the pre-event topography was generated by adding a volume of collapsed material to the collapsed area, as shown in Fig. 6. Furthermore, the same volume was extracted from the present topography along the expected depositional area (Fig. 6). The water surface elevation around the Komagatake Volcano region at that time is unknown; however, this information is not greatly influential given that the tidal amplitude near the area is approximately $0.5 \mathrm{~m}$. Thus, the effect of tides was neglected and the initial water surface elevation was set to zero for this simulation. The computational domain was a rectangular domain with a range of $-253,850$ to $-149,000 \mathrm{~m}$ in north-south direction and $-20,700$ to $121,650 \mathrm{~m}$ in east-west direction in the Japanese plane rectangular coordinate system No. 11. Based on the same processes used for the Oshima-Oshima event, numerical simulations of the tsunami were performed using various values of frictional coefficients. Note that the conditions, such as the model, spatial resolutions, and time step, are the same as those described in the previous section. The computations were performed for $90 \mathrm{~min}$ after the collapse began.

The results of the computations are shown in Figs. 7 and 8. The observational data for the evaluation of $K$ were also based on the database described above. However, there are few data with high reliability for the 1640 Komagatake Tsunami. Thus, it is acceptable to use data in group $\mathrm{Z}$ in addition to groups $\mathrm{A}$ and $\mathrm{B}$. Group $\mathrm{Z}$ means that the information, such as the location, is not quantitative (Iwabuchi et al. 2012). Figure 7 shows that the run-up heights at Uchiura Bay are large. The east side of the Komagatake Volcano has been considered to collapse. The material and generated tsunami radially propagated with the eastern direction as a center according to the numerical simulation; a part of the tsunami with large height entered the bay. The bay was likely to be susceptible to the Komagatake event. Figure 7 and the indexes show that the deviation of the plotted circles is large, because data with uncertainties are included. Therefore, it should be noted that the estimation of the minimum requirement for the Komagatake event might have a low reliability. Figure 8 indicates that both frictional coefficients affect $\mathrm{K}$ but not $\kappa$, similar to the case of the 1741 Oshima-Oshima Tsunami. Hence, no tsunami was simulated when $C_{\mathrm{b}}$ was 0.20 or 0.5 . The collapsed volume in this scenario was approximately $1.2 \mathrm{~km}^{3}$, which was regarded as the requirement to generate this tsunami.

\subsubsection{The Unzen-Mayuyama Event}

The Unzen-Mayuyama Volcano in Nagasaki prefecture collapsed in 1792 due to volcanic activity, which caused a tsunami called the Ariake-Kai Tsunami. This tsunami was the most disastrous of the three tsunami events in this study in terms of human fatalities. More than ten thousand people were killed and the run-up height reached $57 \mathrm{~m}$ (Tsuji and Hino 1993). The topography was constructed using the same data and process as described for the case of the Komagatake Volcano (Fig. 9); Yanagisawa et al. (2014) was quoted to specify the collapsed part of the volcano. However, the topography of the Ariake-Kai Region, including the shoreline, has dramatically changed over the past several decades because of human activities. Additional modifications were added to part of the topography by referring to Japan Cartographers Association (1993), which shows the topography of Japan in the early 1800s. The water surface elevation of the ocean near Ariake-Kai fluctuates with an amplitude of 2-3 $\mathrm{m}$ due to tides. According 

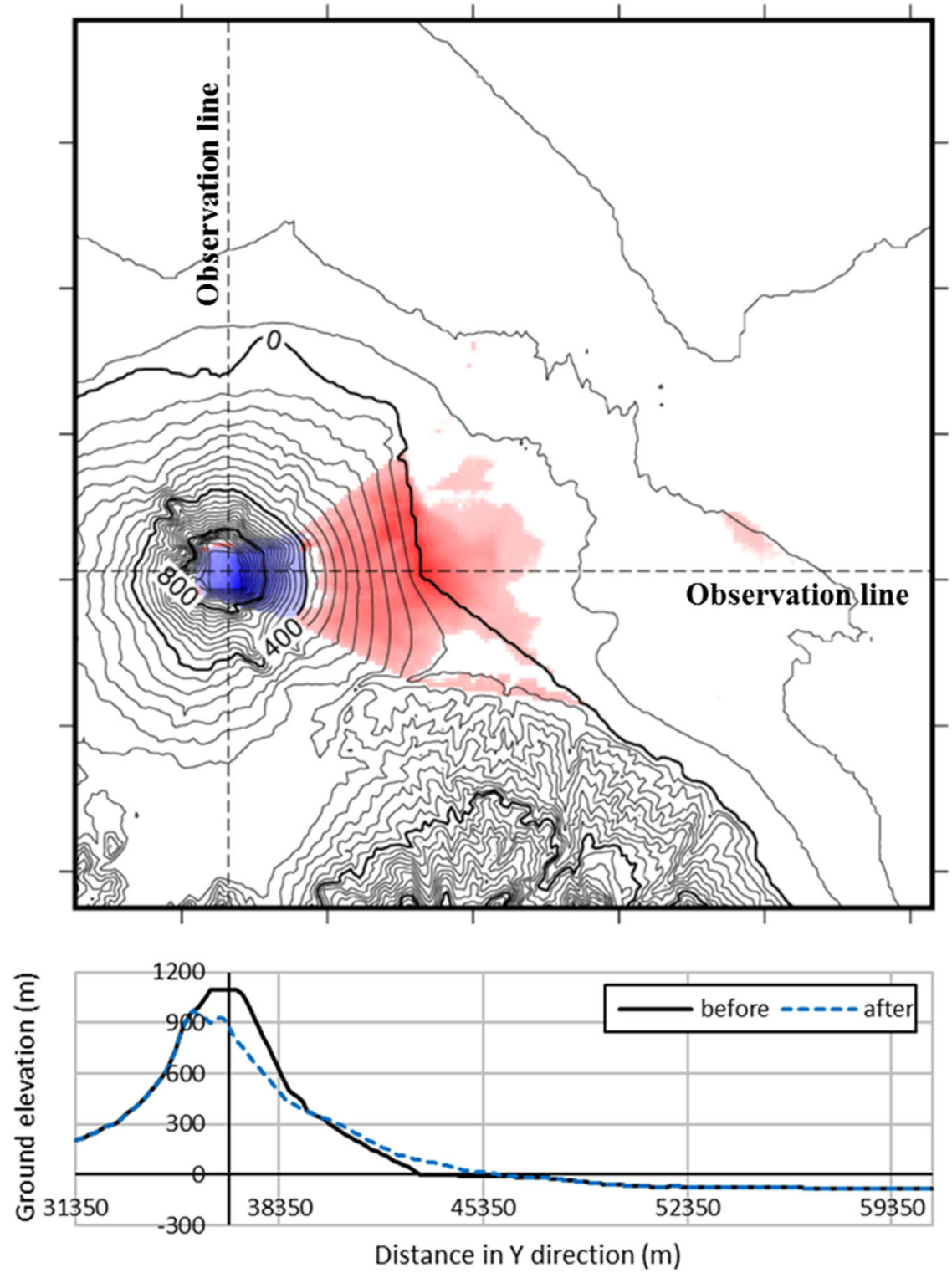

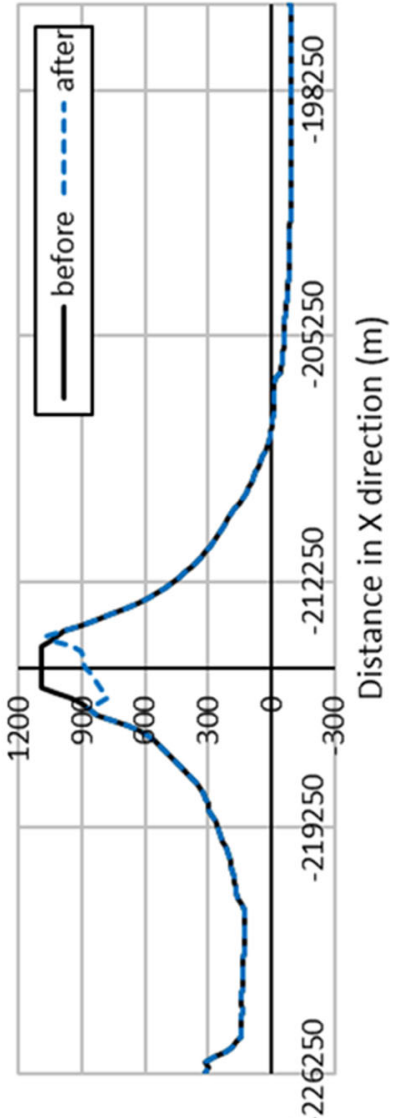

Ground elevation ( $\mathrm{m}$ )

Figure 6

Topography of the Komagatake Volcano (the contour lines, separated by $40 \mathrm{~m}$, show the topography before the collapse; red and blue colors show positive and negative height changes, respectively, of the ground elevation due to the collapse. The graphs show the ground elevation along the observation lines)

to Tsuji and Hino (1993), the water surface elevation at that time was $+1.9 \mathrm{~m}$. The initial water surface elevation was, therefore, set to $+1.9 \mathrm{~m}$. The computational domain was rectangular with a range of $-62,850$ to $30,000 \mathrm{~m}$ in the north-south direction and $52,250-112,150 \mathrm{~m}$ in the east-west direction in the Japanese plane rectangular coordinate system No. 1. Note that the conditions, such as the model, spatial resolutions, and time step, are the same as in the case of the two previously described events. The computations were performed for $90 \mathrm{~min}$ after the collapse began.

The results of the computations are shown in Figs. 10 and 11. The observational data for the evaluation of $K$ were also based on the database described above. Figure 10 shows that the reproduced 


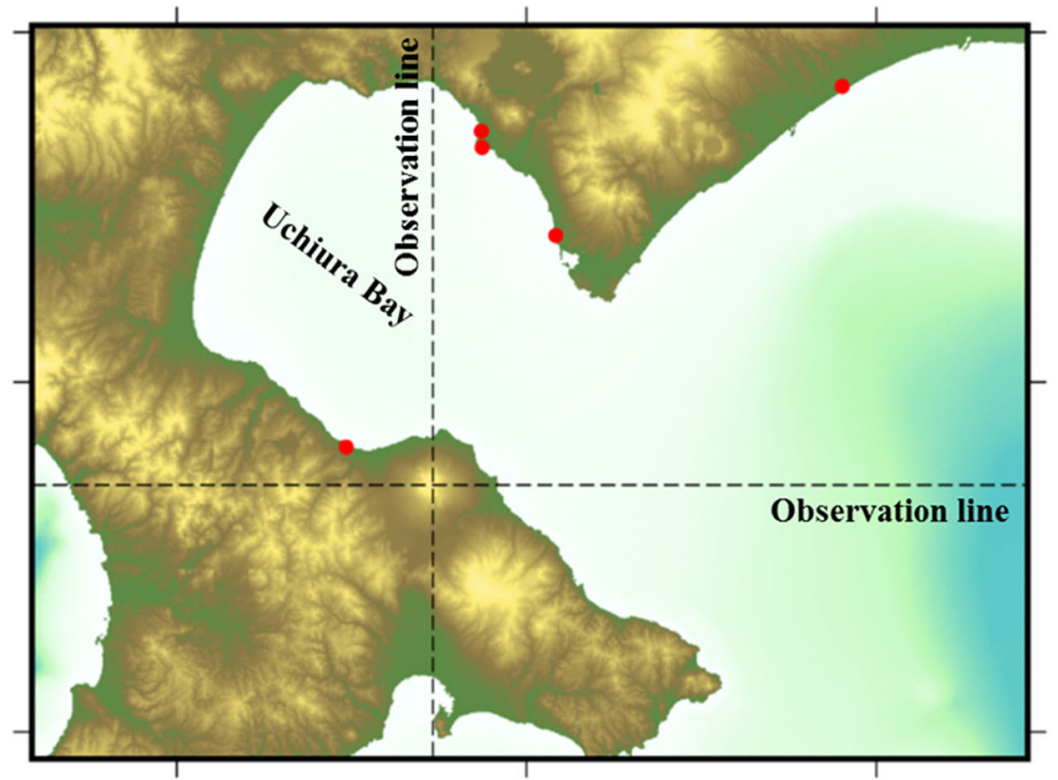

(a)

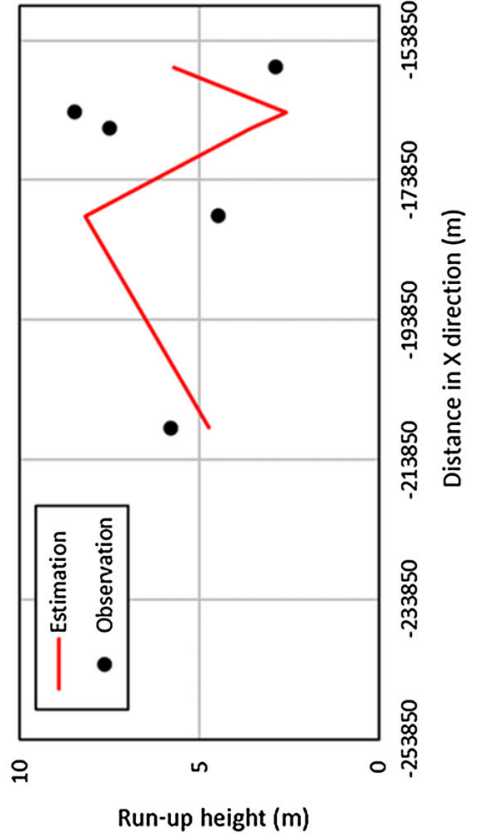

Run-up height (m)

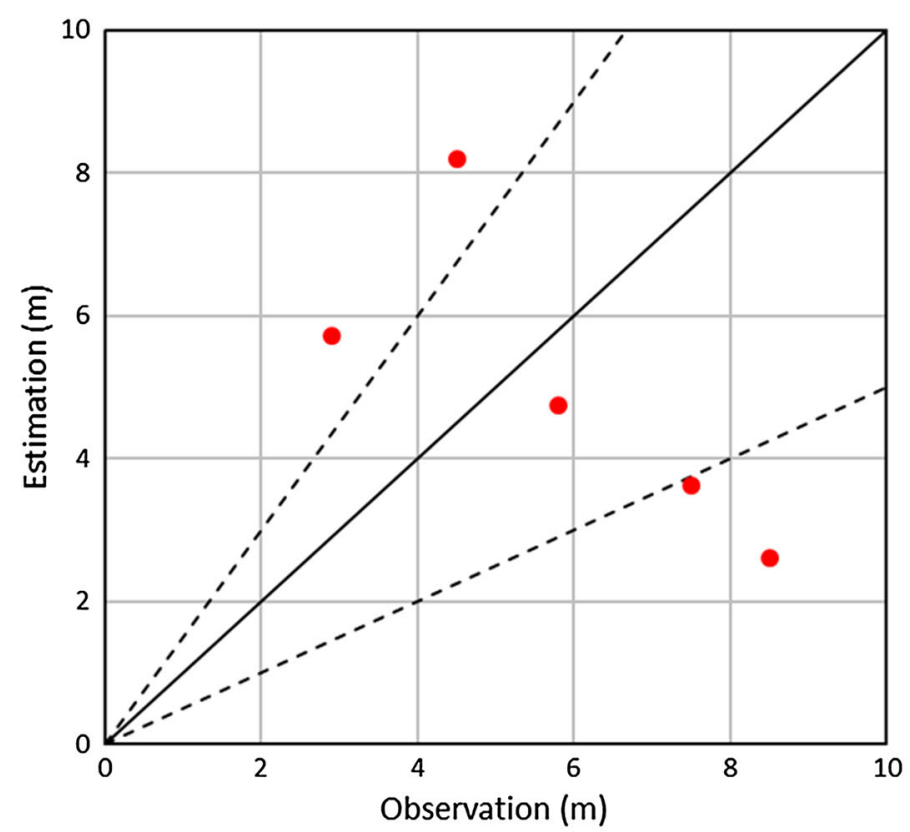

(b)

Figure 7

Results of the computations for the Komagatake event. a Computation domain and distribution of the observed run-up heights (circles). b Comparison of the run-up heights ( $m=5, K=1.18, \kappa=2.07$, in the case of $C_{\mathrm{d}}=C_{\mathrm{b}}=0.01$; the broken lines indicate a $50 \%$ estimation error)

run-up heights are in good agreement for both prefectures. Furthermore, because both indexes are good and the number of data is sufficient, the estimation of the minimum requirement will have a high reliability. Figure 11 shows that both frictional coefficients affect $K$ but not $\kappa$, similar to the above- 


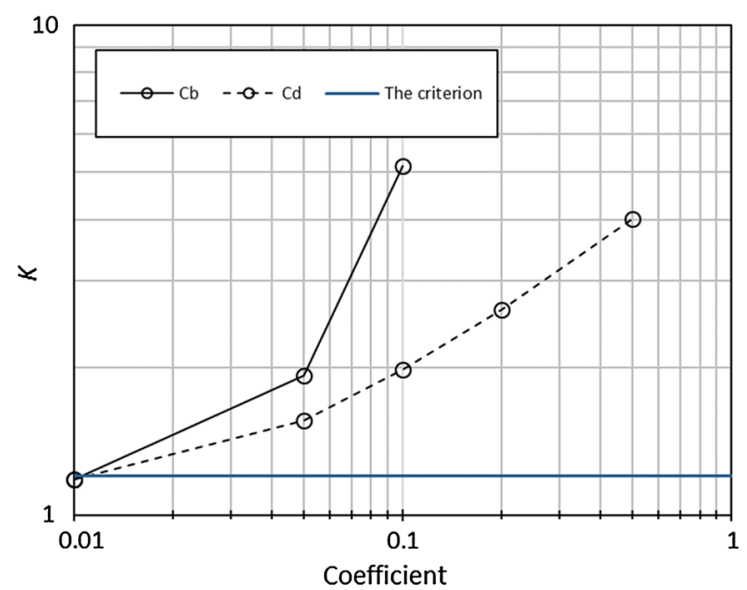

(a)

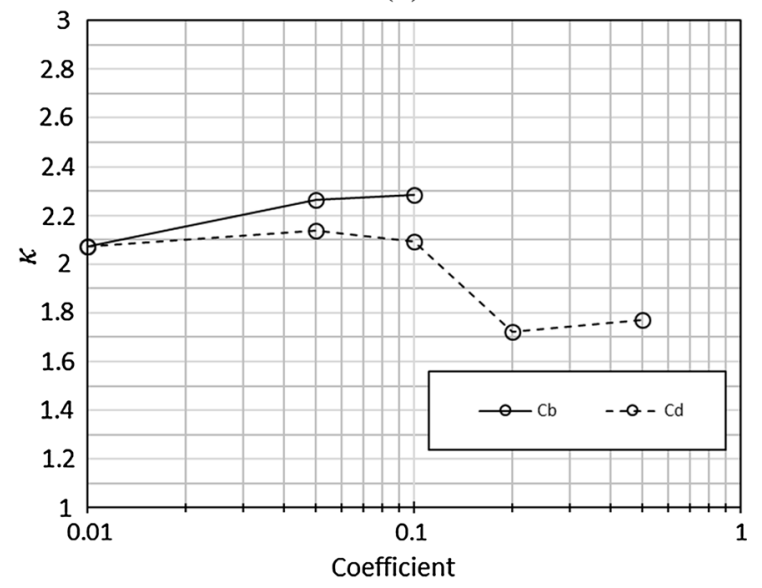

(b)

Figure 8

Sensitivity of the scenarios for the observation depending on the frictional coefficients

mentioned two cases. Based on our numerical simulations, we estimate that a collapsed volume of $0.3 \mathrm{~km}^{3}$ triggered the Ariake-Kai Tsunami.

\section{Discussion}

The inverse model results constrain the collapse volumes that initiated the 1640 Komagatake Tsunami and 1792 Ariake-Kai Tsunami by entering the sea. The estimations reflect minimum collapse volume requirements of 1.2 and $0.3 \mathrm{~km}^{3}$ generating the observed run-up heights, respectively. Nishimura and Satake (1993) performed numerical simulations of the 1640 Komagatake Tsunami assuming that the volume of collapsed volcano material was $0.25 \mathrm{~km}^{3}$; however, Nishimura and Miyaji (1998) noted that this volume was too small, given that the run-up heights estimated by Nishimura and Satake (1993) were significantly smaller than the observed height. Yoshimoto et al. (2003) performed side-scan sonar and seafloor reflection surveys and estimated that the volume of collapsed material of the Komagatake Volcano on the seafloor ranges from 0.92 to $1.20 \mathrm{~km}^{3}$. Thus, our estimation of the volume of collapsed material following the Komagatake event is consistent with previous studies. Considering the possibility that the collapsed materials remained on land, the upper limit of the actual collapsed material might be $>1.20 \mathrm{~km}^{3}$. On the other hand, Inoue (1999) estimated the pre-event topography of the UnzenMayuyama Volcano using historical figures and digital elevation maps, leading to the estimations of the collapsed volume of approximately $0.44 \mathrm{~km}^{3}$. Ota (1969) estimated the collapsed volume to be approximately $0.34 \mathrm{~km}^{3}$ based on historical records. Our estimation of the volume of collapsed material following the 1640 Komagatake event fall within the range of the volume estimated based on previous field and geophysical studies. Yanagisawa et al. (2014) performed a numerical simulation of the Ariake-Kai Tsunami using the pre-event topography based on Inoue (1999) and a two-layer model that requires selective coefficients. Sasahara (2004) also performed a numerical simulation of the tsunami based on the pre-event topography and reported a collapsed volume of approximately $0.4 \mathrm{~km}^{3}$ using a two-layer model similar to Yanagisawa et al. (2014). They successfully reproduced the run-up heights and distributions of the collapsed materials on the seafloor by setting proper coefficient values. However, the possibility that the used pre-event topographies differ from the actual topographies remains, because any run-up height and collapsed material distribution could be reproduced depending on the scenarios and coefficients when the collapsed volume is not smaller, as shown in the case of the Oshima-Oshima event.

Figures 5, 8, and 11 show that, in contrast to $\kappa$, the index $K$ depends on the collapsed volume and frictional coefficients; $\kappa$ is considered to be influenced by the initial height distribution of the 

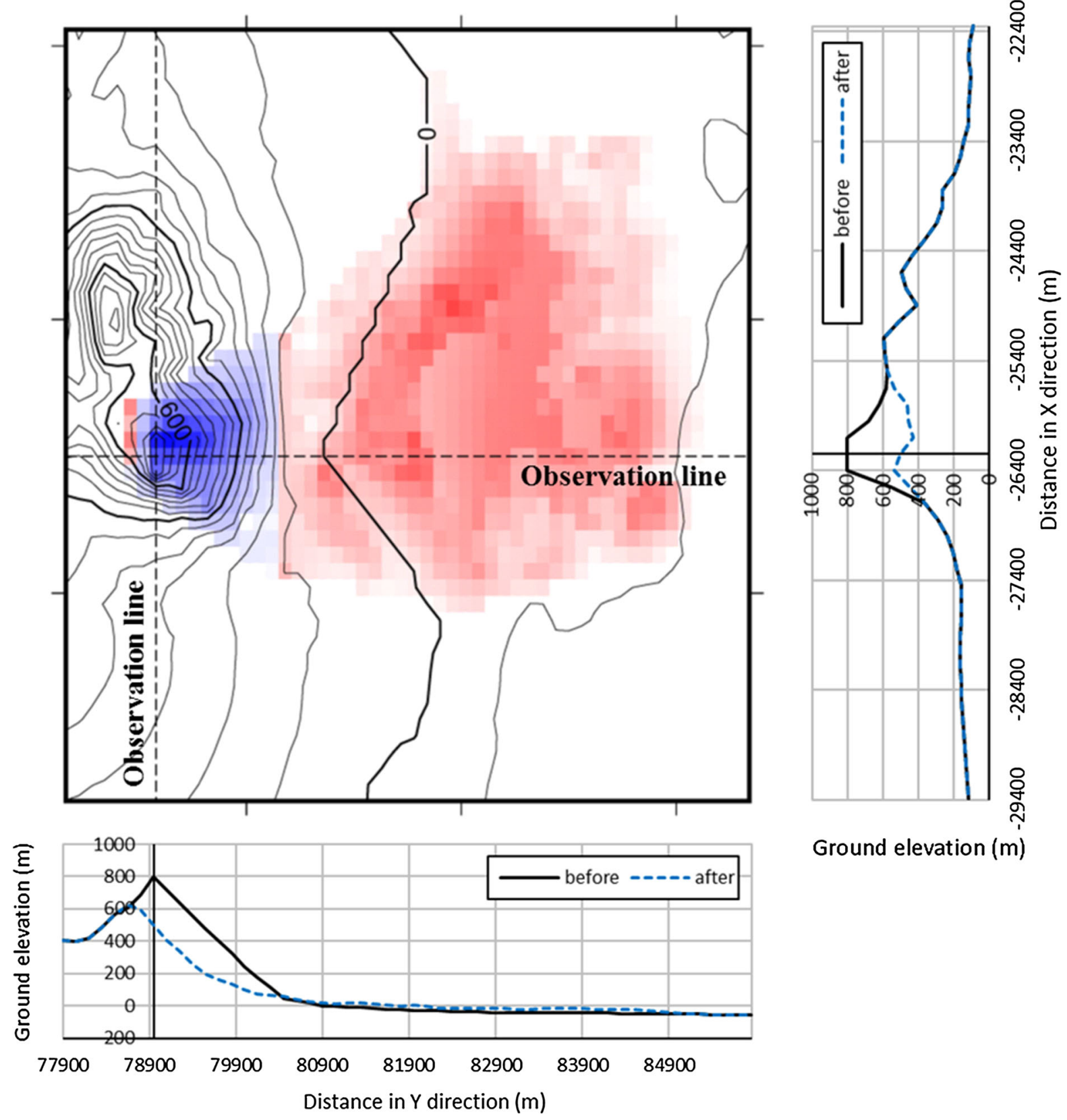

Ground elevation (m)

Figure 9

Topography of the Unzen-Mayuyama Volcano (the contour lines, separated by $50 \mathrm{~m}$, show the topography before the collapse; areas with red and blue colors show positive and negative height changes, respectively, of the ground elevation due to the collapse. The graphs show the ground elevation along the observation lines)

collapsed layer. The moving directions of the collapsed layer at each grid point are expected to change with respect to the distribution of the collapsed layer, because they are mainly determined based on the horizontal slope gradient. The value of $\kappa$ is then expected to decrease by changing the distribution, even for the same collapsed volume. Therefore, $\kappa$ implies the imprecision of the assumed distribution; the assumed topography is more accurate as it decreases. The conditions of the pre-event 


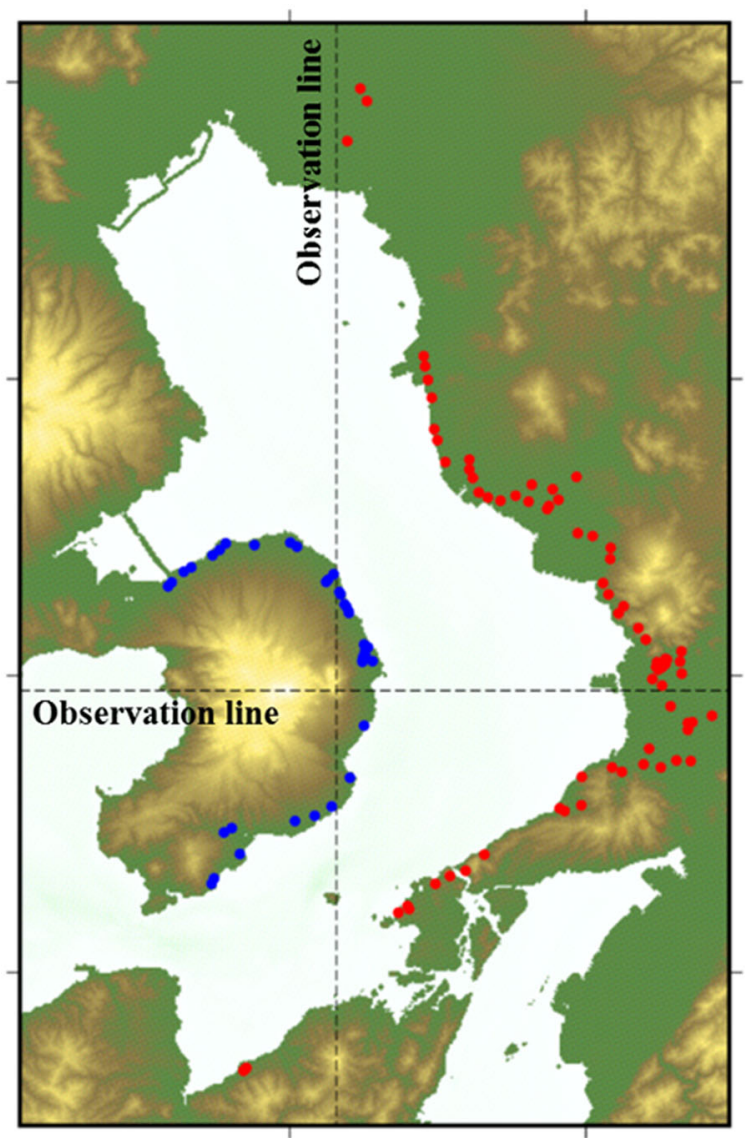

(a)

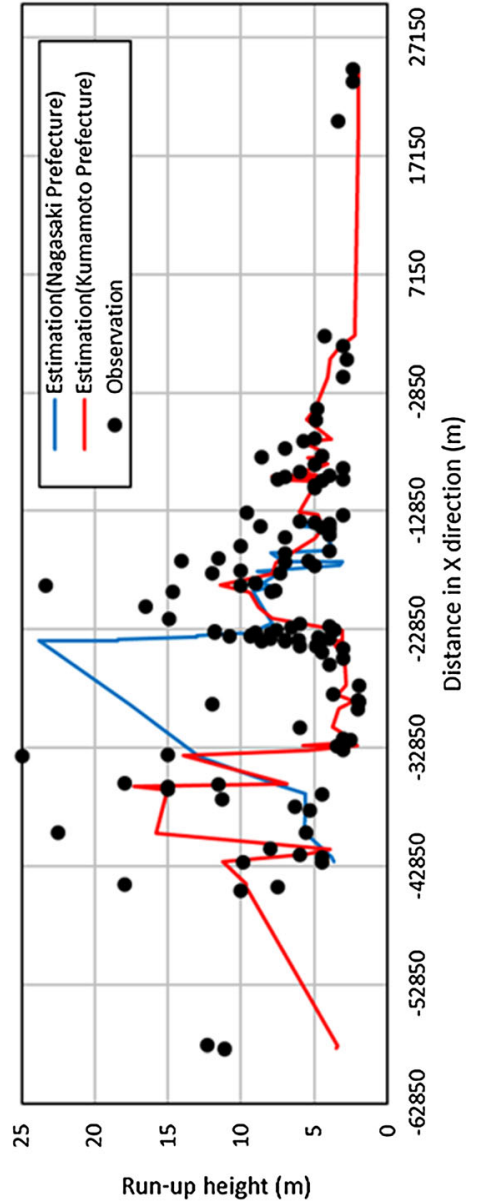

Run-up height (m)

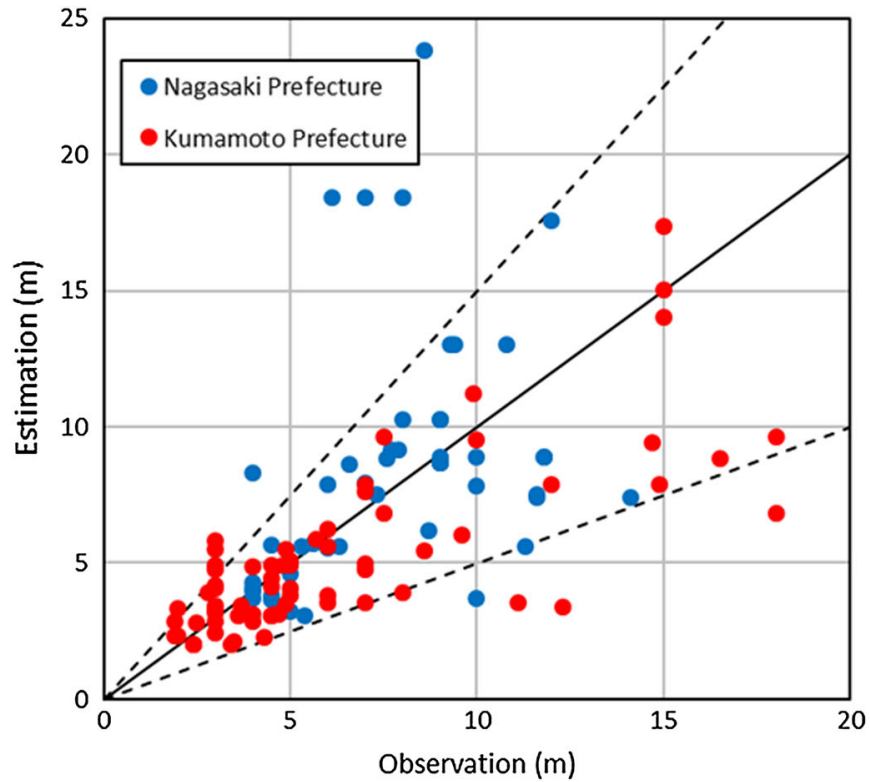

(b) 
Figure 10

Results of the computations for the Unzen-Mayuyama event. a Computation domain and distribution of observed run-up heights (circles). b Comparison of the run-up heights ( $m=117, K=1.09$, $\kappa=1.52$, in the case of $C_{\mathrm{d}}=C_{\mathrm{b}}=0.01$. The broken lines indicate a $50 \%$ estimation error. Note that $K=1.18$ and $\kappa=2.17$ when the height of the water surface elevation due to the tide effect was excluded from the estimation and observation)

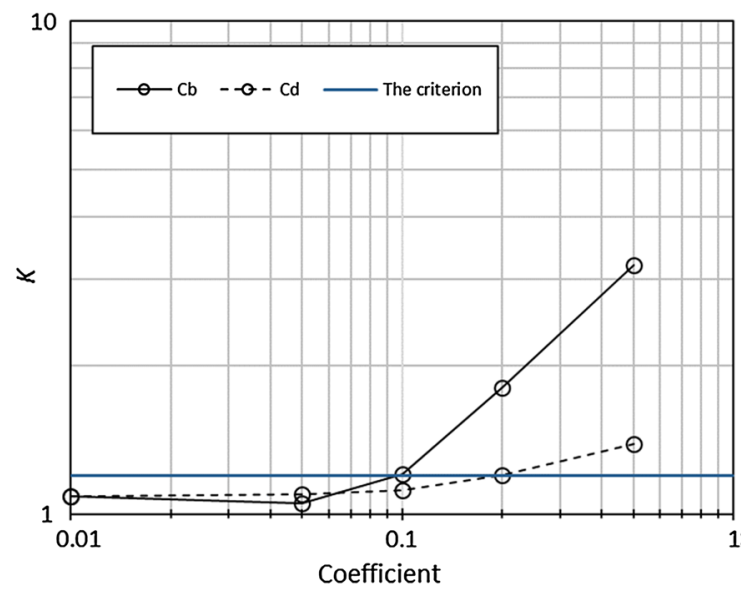

(a)

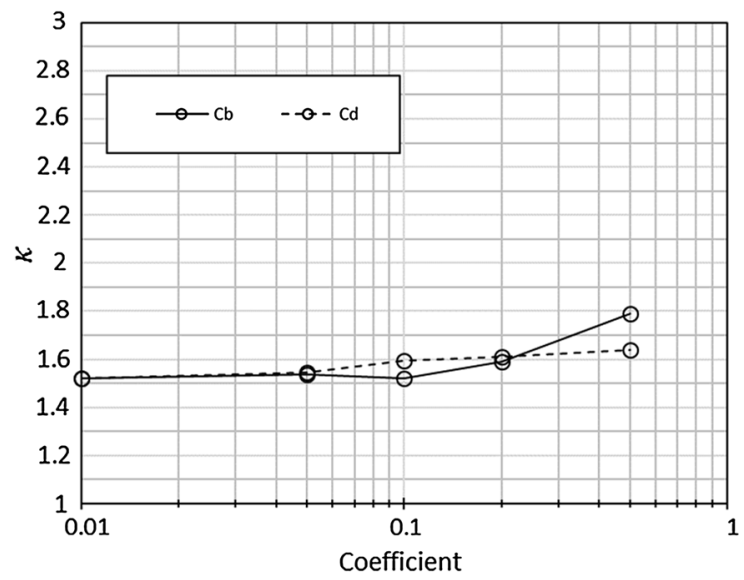

(b)

Figure 11

Sensitivity of the scenarios for the observation depending on the frictional coefficients

topography can be quantitatively evaluated using the requirement and imprecision based on the indexes suggested by Aida (1978). The minimum requirement using the indexes $K$ and $\kappa$ will then be beneficial to estimate and evaluate the collapsed volume and its initial distribution.

\section{Conclusion}

In this study, numerical simulations of the Komagatake, Oshima-Oshima, and Ariake-Kai tsunamis, which were generated by sector collapse, were performed and the pre-event topographies were estimated based on inverse models and observed run-up heights. The main conclusions are summarized below:

1. Numerical simulations of tsunamis were first carried out for the 1741 Oshima-Oshima event, for which a highly reliable topography had been already constructed, to validate the numerical model accuracy and investigate how the run-up height is reproduced as the scenario changes. The computed run-up heights are sensitive to the collapsed volume and frictional coefficients. Replacing frictional coefficient values leads to reasonably accurate run-up heights in the computation, even if the collapsed volume was assumed to be greater than the actual collapsed volume.

2. A minimum required quantity of the collapsed volume generating the observed run-up heights was introduced using an index suggested in Aida (1978). The minimum requirement can be estimated without any physical evidence of the collapse.

3. The minimum requirements of the collapsed volume for the Komagatake and UnzenMayuyama events were estimated to be 1.2 and $0.3 \mathrm{~km}^{3}$, respectively. These values are consistent with volumes that were previously estimated by various methods.

This study provides a methodology involving the estimation of topographic conditions before collapse, which is of advantage in terms of not using any other geological data. Thus, a highly reliable topography is expected to be constructed using the combination of our method with other physical evidence. The upper limit of the collapsed volume remains to be estimated in future work.

\section{Acknowledgements}

We thank Dr. Kenji Satake, who provided us with the topography of the Oshima-Oshima Island before and after the event. This study was supported by the JSPS 
KAKENHI (Grant Number JP-16J00394). This study was also partially supported by the Ministry of Education, Culture, Sports, Science, and Technology (MEXT) of Japan under its Earthquake and Volcano Hazards Observation and Research Program. We would like to thank Editage (www.editage.jp) for English language editing.

Open Access This article is distributed under the terms of the Creative Commons Attribution 4.0 International License (http:// creativecommons.org/licenses/by/4.0/), which permits unrestricted use, distribution, and reproduction in any medium, provided you give appropriate credit to the original author(s) and the source, provide a link to the Creative Commons license, and indicate if changes were made.

\section{REFERENCES}

Aida, I. (1978). Reliability of a tsunami source model derived from fault parameters. Journal of Physics of the Earth, 26, 57-73.

Baba,T., Takahashi, N., Kaneda, Y., Ando, K., Matsuoka, D., \& Kato, T. (2015). Parallel implementation of dispersive tsunami wave modeling with a nesting algorithm for the 2011 Tohoku tsunami. Pure and Applied Geophysics, 172(12), 3455-3472.

de la Asunción, M., Castro, M. J., Mantas, J. M., \& Ortega, S. (2016). Numerical simulation of tsunamis generated by landslides on multiple GPUs. Advances in Engineering Software, 99, 59-72.

Fritz, H. M., Hager, W. H., \& Minor, H.-E. (2001). Lituya Bay case: Rockslide impact and wave run-up. Science of Tsunami Hazards, 19(1), 3-22.

Fritz, H. M., Hager, W. H., \& Minor, H.-E. (2003a). Landslide generated impulse waves. 1. Instantaneous flow fields. Experiments in Fluids, 35, 505-519.

Fritz, H. M., Hager, W. H., \& Minor, H.-E. (2003b). Landslide generated impulse waves. 2. Hydrodynamic impact craters. $E x$ periments in Fluids, 35, 520-532.

Fritz, H. M., Hager, W. H., \& Minor, H.-E. (2004). Near field characteristics of landslide generated impulse waves. Journal of Waterway, Port, Coastal, and Ocean Engineering, 130(6), 287-302.

Fritz, H. M., Mohammed, F., \& Yoo, J. (2009). Lituya Bay landslide impact generated mega-tsunami 50th anniversary. Pure and Applied Geophysics, 166(1), 153-175.

Goto, C., Ogawa, Y., \& Imamura, F. (1997). Numerical method of tsunami simulation with leap-frog scheme (IUGG/IOC Time Project). IOC Manual, UNESCO, No. 35, Part 1.

Hatori, T. (1984). Reexamination of wave behavior of the Hokkaido-Oshima (the Japan Sea) Tsunami in 1741: Their comparison with the 1983 Nihonkai-Chubu Tsunami. Bulletin of Earthquake Research Institute University of Tokyo, 59, 115-125. (written in Japanese).

Heller, V., \& Spinneken, J. (2013). Effects of block model parameters and slide model. Journal of Geophysical Research: Oceans, 118, 1489-1507.
Hirayama, H., \& Hiraishi, T. (2004). Boussinesq modeling of wave breaking and run-up on a reef; 1D. Annual Journal of Coastal Engineering, JSCE, 51, 11-15. (written in Japanese).

Inoue, K. (1999). Shimabara-Shigatusaku Earthquake and topographic changes by Shimabara Catastrophe in 1792. Journal of the Japan Society of Erosion Control Engineering, 52(4), 45-54. (written in Japanese with English abstract).

Japan Cartographers Association (1993). Ino-zu, BUYODO (written in Japanese).

Iwabuchi, Y., Sugino, H., Imamura, F., Tsuji, Y., Matsuoka, Y., Imai, K., et al. (2012). Development of a tsunami trace database with reliability evaluation on Japan coasts. Journal of JSCE, Series B2 (Coastal Engineering), 68(2), 1326-1330. (written in Japanese with English abstract).

Johnson, R. W. (1987). Large-scale volcanic cone collapse: The 1888 slope failure of the Ritter volcano, and other examples from Papua New Guinea. Bulletin of Volcanology, 49(5), 669-679.

Kato, Y. (1997). Topography and geology of the sector collapse deposit of the Oshima-Oshima. JAMSTEC Journal of Deep Sea Research, 13, 659-667 (written in Japanese with English abstract).

Kawamata, K., Takaoka, K., Ban, K., Imamura, F., Yamaki, S., \& Kobayashi, E. (2005). Model of tsunami generation by collapse of volcanic eruption: The 1741 Oshima-Oshima Tsunami. In K. Satake (Ed.), Tsunamis: Case Studies and Recent Developments (pp. 79-96). New York: Springer.

Kirby, J. T., Shi, F., Nicolsky, D., \& Misra, S. (2016). The 27 April 1975 Kitimat, British Columbia, submarine landslide tsunami: A comparison of modeling approaches. Landslides, 13, 1421-1434.

Løvholt, F., Pedersen, G., \& Gisler, G. (2008). Oceanic propagation of a potential tsunami from the La Palma Island. Journal of Geophysical Research, 113, C09026.

Lowder, G. G., \& Carmichael, I. S. E. (1970). The volcanoes and caldera of Talasea. New Britain: Geology and Pettology, Geological Society of America Bulletin, 81(1), 17-38.

McFall, B.C. \& Fritz, H.M. (2016). Physical modelling of tsunamis generated by three-dimensional deformable granular landslides on planar and conical island slopes. In: Proc. R. Doc. A., 472(2188), The Royal Society, 20160052, 2016.

Miller, D. J. (1960). Giant waves in Lituya Bay, Alaska. U.S. Geological Survey Professional Paper, 354, 51-86.

Mohammed, F., \& Fritz, H. M. (2012). Physical modeling of tsunami generated by three-dimensional deformable granular landslides. Journal of Geophysical Research, 117, C11015.

Nishimura, Y., \& Miyaji, N. (1995). Tsunami deposits from the 1993 Southwest Hokkaido Earthquake and the 1640 Hokkaido Komagatake Eruption, Northern Japan, In: Tsunamis: 19921994. Birkhäuser Basel, pp. 719-733.

Nishimura, Y., \& Miyaji, N. (1998). On height distribution of tsunami caused by the 1640 Eruption of Hokkaido-Komagatake, Northern Japan. Bulletin of the Volcanological Society of Japan, 43(4), 239-242. (written in Japanese).

Nishimura, Y. \& Satake, K. (1993). Numerical computations of tsunamis from the past and future eruptions of Komagatake, Hokkaido, Japan. In Proceedings of the IUGG/IOC International Tsunami Symposium, pp. 573-583.

Ôta, K. (1969). Study on the collapses in the Mayu-yama: 1. On the mechanism of collapse, Bulletin of Shimabara Institution of Volcanology and Balneology, Faculty of Science, Kyushu University, 5, 6-35. (written in Japanese with English abstract). 
Roverato, M., Capra, L., Sulpizio, R., \& Norini, G. (2011). Stratigraphic reconstruction of two debris avalanche deposits at Colima Volcano (Mexico): Insights into pre-failure conditions and climate influence. Journal of Volcanology and Geothermal Research, 207, 33-46.

Sælevik, G., Jensen, A., \& Pedersen, G. (2009). Experimental investigation of impact generated tsunami; related to a potential rock slide. Western Norway, Journal of Coastal Engineering, 56, 897-906.

Saito, T., Inazu, D., Miyoshi, T., \& Hino, R. (2014). Dispersion and nonlinear effects in the 2011 Tohoku-Oki earthquake tsunami. Journal of Geophysical Research: Oceans, 119(8), 5160-5180.

Sako, Y., Mori, T., Nakamura, H., Yusa, N., Ohno, R., Fukuda, M., et al. (2015). An estimation of the shape of landslide dam caused by deep-seated landslide. Journal of the Japan Society of Erosion Control Engineering, 68(1), 44-51. (written in Japanese with English abstract).

Sasahara, N. (2004). Numerical simulation of the tsunami caused by the sector collapse of Mt. Mayuyama, Shimabara Peninsula Kyushu in 1792. Report of Hydrographic and Oceanographic Researches, 40, 63-72. (written in Japanese with English abstract).

Satake, K. (2007). Volcanic origin of the 1741 Oshima-Oshima tsunami in the Japan sea. Earth, Planets and Space, 59, 381-390.

Satake, K., \& Kato, Y. (2001). The 1741 Oshima-Oshima eruption: Extent and volume of submarine debris avalanche. Geophysical Research Letters, 28(3), 427-430.

Sato, S. (1996). Numerical simulation of 1993 Southwest Hokkaido Earthquake Tsunami around Okushiri Island. Journal of Waterway, Port, and Coastal Engineering, 122(5), 209-215.

Tinti, S., Bortolucci, E., \& Romagnoli, C. (2000). Computer simulations of tsunamis due to sector collapse at Stromboli, Italy. Journal of Volcanology and Geothermal Research, 96, 103-128.

Tsuji, Y., \& Hino, T. (1993). Damage and inundation height of the 1792 Shimabara Landslide Tsunami along the coast of Kumamoto Prefecture. Bulletin of Earthquake Research Institute University of Tokyo, 68, 91-176. (written in Japanese with English abstract).

Voight, B. (1981). Time scale for the first moments of the May 18 eruption. U.S. Geological Survey Professional Paper, 1250, 69-86.

Voight, B., Glicken, H., Janda, R., \& Douglass, P. M. (1981). Catastrophic rock slide avalanche of May 18: In the 1980 Eruptions of Mount St. Helens, Washington. U.S. Geological Survey Professional Paper, Paper 1250, 347-377.
Voight, B., Janda, R. J., Glicken, H., \& Douglass, P. M. (1983). Nature and mechanics of the Mount St Helens rockslideavalanvhe of 18 May 1980. Géotechnique, 33, 243-273.

Ward, S. N., \& Day, S. (2003). Lateral collapse and the tsunami of 1888. Geophysical Journal International, 154, 891-902.

Watts, P., Grilli, T., Kirby, J. T., Fryer, G. J., \& Tappin, D. R. (2003). Landslide tsunami case studies using a boussinesq model and a fully nonlinear tsunami generation model. Natural Hazzards and Earth System Science, 3, 391-402.

Weiss, R., Fritz, H. M., \& Wünnemann, K. (2009). Hybrid modeling of the mega-tsunami runup in Lityua Bay after half a century. Geophysical Research Letters, 36, L09602.

Xenakis, A. M., Lind, S. J., Stansby, P. K., \& Rogers, B. D. (2017). Landslides and tsunamis predicted by incompressible smoothed particle hydrodynamics (SPH) with application to the 1958 Lituya Bay event and idealized experiment. Proceedings of the Royal Society A, 473(2199), 20160674.

Xiao, L., Ward, S. N., \& Wang, J. (2015). Tsunami squares approach to landslide-generated waves: Application to Gongjiafang landslide. Three Gorges Reservoir, China, Pure and Applied Geophysics, 172, 3639-3654.

Yanagisawa, H., Aoki, A., Sassa, K., \& Inoue, K. (2014). Numerical simulation of 1792 Ariake-Kai Tsunami using landslide tsunami model. Journal of JSCE Series B2 (Coastal Engineering), 70, 151-155 (written in Japanese with English abstract).

Yoshimoto, M., Furukawa, R., Nanayama, F., Nishimura, Y., Nishina, K., Uchida, Y., et al. (2003). Subaqueous distribution and volume estimation of the debris-avalanche deposit from the 1640 eruption of Hokkaido-Komagatake volcano, southwest Hokkaido, Japan. The Journal of the Geological Society of Japan, 109(10), 595-606. (written in Japanese with English abstract).

Zaniboni, F., Armigliato, A., \& Tinti, S. (2016). A numerical investigation of the 1783 landslide-induced catastrophic tsunami in Scilla, Italy. Nature Hazards, 84, 455-470.

Zaniboni, F., Pagnoni, G., Tinti, S., Seta, M. D., Fredi, P., Marotta, E., et al. (2013). The potential failure of Monte Nuovo at Ischia Island (Southern Italy): numerical assessment of a likely induced tsunami and its effects on a densely inhabited area. Bulletin of Volcanology, 75(11), 763.

Zhou, H., Moore, C. W., Wei, Y., \& Titov, V. V. (2011). A nestedgrid Boussinesq-type approach to modeling dispersive propagation and runup of landslide-generated tsunamis. Natural Hazards and Earth System Sciences, 11, 2677-2697. 